\title{
A genetic study of von Recklinghausen neurofibromatosis in south east Wales. I Prevalence, fitness, mutation rate, and effect of parental transmission on severity
}

\begin{abstract}
S M HUSON*, D A S COMPSTON†, P CLARK
From the Institute of Medical Genetics*, and Section of Neurology†, University of Wales College of Medicine, Heath Park, Cardiff CF4 $4 X N$; and $\ddagger$ the Section of Medical Statistics, Clinical Research Centre, Watford Road, Harrow HA1 3UJ.
\end{abstract}

SUMMARY A population based study of von Recklinghausen neurofibromatosis in south east Wales (population 668 100) identified 69 families with 135 affected members (prevalance 1/4950 of the population). In these families penetrance of the NF-1 gene was $100 \%$ by the age of five years. The genetic fitness of NF-1 sufferers was found to be reduced to $0 \cdot 47$, the effect being more marked in males than females $(f=0.31$ and 0.60 , respectively). Forty-one of 135 cases were judged to represent new disease mutations and the mutation rate was estimated to lie between $3 \cdot 1 \times 10^{-5}$ and $10 \cdot 4 \times 10^{-5}$. A parental age effect for new mutations was not found, nor was a maternal effect on disease severity.

The first family in which von Recklinghausen neurofibromatosis (NF-1) occurred in more than one generation was probably that reported by Virchow ${ }^{1}$ in 1847. Thomson ${ }^{2}$ undertook a systematic genetic study in 1900 , showing that the disease was familial in 30 of 77 reported cases. Preiser and Davenport ${ }^{3}$ studied the frequency of NF-1 in children of affected cases in published reports; they found that 50/115 $(44 \%)$ were affected, with no difference in the sex distribution and many instances of male to male transmission. It was concluded that inheritance was autosomal dominant.

The first large clinical studies of the disease were reported by Borberg ${ }^{4}$ in 1951 and Crowe et $a l^{5}$ in 1956. Both found autosomal dominant inheritance with high penetrance and just over half the probands in each series represented new mutations. The study of Crowe et al ${ }^{5}$ was particularly important for two reasons. They appreciated that both multiple café au lait (CAL) spots and axillary freckling ${ }^{6}$ were major features of the disease; they were also the first to estimate the frequency of the disease $(1 / 2500$ to $1 / 3300)$ and mutation rate $\left(1 \times 10^{4}\right.$ per gamete per generation, the highest known for a human disorder).

Received for publication 15 November 1988.

Revised version accepted for publication 27 June 1989.
Two subsequent studies ${ }^{78}$ have found the disease to be less prevalent and the mutation rate (table 1) more in line with estimates for other disorders.

The last decade has seen increasing awareness of the problems encountered in diagnosis and management of the different forms of neurofibromatosis. ${ }^{9} 10$ Modern clinical and laboratory techniques have been applied to the disease, culminating in 1987 with the mapping of the genes for NF-1 and bilateral acoustic neurofibromatosis (NF-2) to chromosomes $17^{11} 12$ and $22,,^{13}{ }^{14}$ respectively. Our interest in NF-1 arose through genetic linkage studies. ${ }^{15}$ Reviewing published reports at the outset, it became apparent

TABLE 1 Summary of previous estimates of prevalence and mutation rate for von Recklinghausen neurofibromatosis.

\begin{tabular}{|c|c|c|c|}
\hline $\begin{array}{l}\text { Study } \\
\text { (year) }\end{array}$ & $\begin{array}{l}\text { Method of } \\
\text { ascertainment }\end{array}$ & Prevalence & $\begin{array}{l}\text { Mutation rate } \\
\text { (method) }\end{array}$ \\
\hline Crowe et al $l^{5}(1956)$ & $\begin{array}{l}\text { Surveys of general } \\
\text { hospital admissions } \\
\text { and state mental } \\
\text { institutions }\end{array}$ & $s^{1 / 2500-3300}$ & $\begin{array}{l}1.4-2.6 \times 10^{-4} \\
(\text { direct }) \\
0.7-0.9 \times 10^{-4} \\
(\text { indirect. } \mathrm{f}=0.53)\end{array}$ \\
\hline Sergeyev $^{7}(1975)$ & $\begin{array}{l}\text { Population sample } \\
\text { of } 16 \text { year old } \\
\text { youths }\end{array}$ & $1 / 7800$ & $\begin{array}{l}4.4-4.9 \times 10^{-5} \\
(\text { direct) }\end{array}$ \\
\hline $\begin{array}{l}\text { Samuelsson and } \\
\text { Axelsson }^{\varnothing}(1981)\end{array}$ & Population based & $1 / 4600$ & $\begin{array}{c}4.3 \times 10^{-5} \\
(\text { direct })\end{array}$ \\
\hline
\end{tabular}


that information relating to genetic aspects of the disease was far from complete. Previous studies had reported contradictory findings on certain aspects (for example, maternal effect on severity), ${ }^{16-18}$ had not distinguished between different forms of neurofibromatosis, ${ }^{58}$ or had looked at the incidence of complications in patients ascertained via hospital practice, ${ }^{19}$ producing bias towards severely affected subjects. Alongside linkage studies, we therefore undertook a population based study of the disease in south east Wales. The clinical aspects of the study have been reported in detail elsewhere ${ }^{20}$; in this paper we report the genetic analysis of this population.

\section{Methods}

The study was carried out between October 1983 and February 1986 in South Glamorgan and the west part of Gwent. Index cases were ascertained by contacting general practitioners and relevant consultants working in the study area and by reviewing the case notes of patients identified by the inpatient activity analysis of hospitals serving the study area, available from 1969. The records of patients treated for scoliosis and pseudoarthrosis from 1954 at the main orthopaedic hospital in the study area were reviewed, as were the records of patients identified through the neuropathology register and dermatology histology index (available from 1972) at the University Hospital of Wales as having had a tumour removed, which could have been associated with NF-1. Finally the records were checked of all families seen for genetic counselling at the University Hospital of Wales since 1972.

After obtaining permission from the general practitioners, the index cases were contacted by letter and those who agreed to take part were assessed clinically on a domiciliary or outpatient basis by one of us (SMH). If the diagnosis of NF-1 was confirmed, a family study was undertaken and all consenting first degree relatives living within the study area were examined. Relatives of index cases who had died before the study started and whose hospital records indicated a positive family history were contacted through their general practitioner.

The criteria used for diagnosing NF-1 were that an affected subject had two or more of the following: (1) six or more CAL spots measuring more than $1.5 \mathrm{~cm}$ in diameter, or more than $0.5 \mathrm{~cm}$ in diameter if the patient was 14 years or under; (2) axillary freckling; (3) two or more dermal neurofibromas; (4) a plexiform neurofibroma; (5) a first degree relative with NF-1 (based on criteria 1 to 4 ).

In assessing relatives of index cases who had fewer than six CAL spots and no other features, the diagnosis was considered equivocal in those aged five years or under with one to five CAL spots and those aged over five years with three to five CAL spots, whereas subjects aged over five years with one or two CAL spots were classified as normal.

Lisch nodules were not used as a diagnostic criterion, since at the outset of the study only one previous report $\mathrm{t}^{21}$ had assessed their frequency in a large series of NF-1 cases and their incidence in the general population was not known. A portable slit lamp was available for part of the study and the assessment protocol included slit lamp examination of the iris if this was possible.

Affected subjects were assigned to a severity grade for the disease. The grading system used was developed from the one used by Riccardi and Kleiner, ${ }^{22}$ the patients being assigned to a given grade if they had any one of the disease features or complications listed for the grade.

Grade 1 (minimal): CAL spots only, or with unobtrusive cutaneous neurofibromas.

Grade 2 (mild): numerous cutaneous neurofibromas but without facial disfigurement; small plexiform neurofibromas with no associated problems; asymptomatic osseous lesions; learning difficulties with normal IQ.

Grade 3 (moderate): numerous cutaneous neurofibromas with facial disfigurement; plexiform neurofibromas with modest localised hypertrophy; visceral neurofibromas; mild retardation; scoliosis or pseudoarthrosis requiring surgery; controlled epilepsy.

Grade 4 (severe): disease complications leading to major health impairment, often requiring surgical intervention, for example, large plexiform neurofibromas with severe secondary problems, CNS tumours, malignancy, aqueduct stenosis, severe mental retardation, phaeochromocytoma, and renal artery stenosis.

Unless stated the statistical methods used for the genetic analyses were taken from Emery. ${ }^{23}$ For ease of comprehension the methods used are described in each section of results.

\section{Results}

After exclusions based on insufficient criteria for the diagnosis of NF-1 (seven cases, all personally examined), alternative diagnosis (17 cases, all personally examined), moved from area (1), or difficulty in tracing (1), the diagnosis of NF-1 was accepted in 93 of 119 originally ascertained cases. In 
77 of 93 index cases the diagnosis was confirmed by personal examination; six index cases did not wish to be examined but allowed medical and family details to be accessed from their general practitioner/hospital records. The diagnosis was confirmed in all cases. The remaining 10 index cases had died before the study but the diagnosis was accepted on good circumstantial evidence from hospital records; in three out of 10 of these cases one or more first degree relatives had been independently ascertained.

The 93 NF-1 index cases came from 75 families; in six of these, where the index case was dead, no affected relatives living within the study area were identified through hospital records or contact with their general practitioner. Family studies were undertaken on the remaining 69 families, in 13 of which there were two or more index cases. Fifty-two affected relatives (48 personally examined) were ascertained living within the study area.

Therefore a total of 135 subjects (60 males and 75 females) with NF-1 were identified living in the study area ( 83 index cases and 52 affected relatives).

\section{PEDIGREE ANALYSIS}

The pedigrees confirmed the autosomal dominant inheritance of NF-1. There were numerous examples of male to male transmission and segregation analysis, in families where the index case was an adult and all their offspring had been examined, showed no departure from the expected 1:1 ratio (23/47 children affected).

There were 45 instances of three generation and one of four generation transmission of the disease; in all cases the intervening parent(s) had appropriate manifestations of the disease for their age. The only situation in which difficulty in classification of an at risk subject arose was in young children with between one and five CAL spots and no other features. Four such children (aged six years or under) were identified, classified as being equivocal, and excluded from further analysis.

Forty-one index cases, six affected parents, and one affected grandparent gave no history of NF-1 in their sibs or in preceding generations. Examination of the parents and children of these cases was undertaken wherever possible. The patients were often reluctant to involve their sibs in the study, being adamant that in all cases they were unaffected. Detailed pedigree information is given for these 48 'sporadic' cases in the appendix; there was sufficient information for 41 out of 48 to assume that they represent new mutations of the NF-1 gene. Segregation analysis in the families of the 14 new mutations, where all the children were examined and classified unequivocally, showed no significant departure from the expected $1: 1$ ratio $\left(16 / 29\right.$ affected: $\chi^{2}=0 \cdot 14$, $\mathrm{p}=0.71)$.

DISEASE PREVALENCE

On prevalence day (1 June 1985) the population of the study area, taken from the mid year estimates of the Office of Population Censuses and Surveys, was 668100 giving a minimum prevalence of $135 / 668100$, that is $1 / 4950$ or $20 \cdot 2 / 10^{5}$ of the population.

The methods of ascertainment used could, however, have been expected to 'miss' mildly affected cases, particularly children who were new mutations and had no major disease complications. This possibility was examined by comparing the ratio of new mutations to familial cases with age; this showed marked disparity. Excluding the seven cases in whom details of inheritance were uncertain, five of $45(11 \%)$ cases aged less than 20 years were new mutations (ratio $1: 8 \cdot 0$ ), compared with 36 of 83 $(43 \%)$ cases aged 20 years or over (ratio $1: 1 \cdot 3$ ). To bring these two ratios to equality would require 26 further cases aged less than 20 years. If it is assumed that these 26 cases were 'missed' by the study, the corrected prevalence is $161 / 668100$, that is, $1 / 4150$ or $24 \cdot 1 / 10^{5}$ of the population.

ESTIMATION OF FITNESS IN NF-1 This was done by the method of Tanaka ${ }^{24} 25$ and the analysis is given in the appendix. The relative fitness of NF-1 sufferers was 0.470 overall. The fitness of male sufferers $(0.307)$ was markedly reduced compared with females $(0 \cdot 597)$.

MUTATION RATE OF THE NF-1 GENE Direct method: $41 / 135$ cases of NF-1 identified in the study population (668 100) represent probable new mutations of the disease gene. The mutation rate ( $\mu, \pm 95 \%$ confidence interval; Emery, ${ }^{23}$ p 33) is therefore equal to:

$$
\begin{aligned}
& \mu=\frac{41}{1336200} \\
& \mu=(3.07, \pm 0.94) \times 10^{-5} .
\end{aligned}
$$

In view of the probable underascertainment of children who represent new mutations, the mutation rate was also calculated having corrected for this by adding the 26 'missed' NF-1 cases, presumed to be new mutations, to the 41 actually identified:

$$
\mu=\frac{67}{1336200}=(5 \cdot 01, \pm 1 \cdot 20) \times 10^{-5} \text {. }
$$

Indirect method: this calculation (Emery, ${ }^{23} \mathrm{p} 34$ ) requires the incidence of the NF-1 gene at birth, and 
this is unknown. However, given that the complications of NF-1 that cause death in childhood are rare, we have calculated the prevalence in those aged less than 20 years and assumed that this approximates to incidence.

Forty-six cases were ascertained aged less than 20 years from a population of 184200 , giving a minimum prevalence in this age group of 0.000250 or $1 / 4000$.

Adding the 26 paediatric cases that we have shown were 'missed' by the study methods gives a maximum prevalence of $72 / 184200,0.000391$ or $1 / 2558$ of the population. Therefore:

(1) Using minimum prevalence at less than 20 years as $\equiv$ incidence

$$
\begin{aligned}
& \mu=1 / 2 \text { I }(1-f), \\
& \text { where } I=\text { incidence and } f=\text { fitness of NF-1 } \\
& \mu=0.000125(0 \cdot 53) \\
& \mu=6.62 \times 10^{-5} .
\end{aligned}
$$

(2) Using maximum prevalence at less than 20 years as $\equiv$ incidence

$$
\begin{aligned}
& \mu=0.0001955(0.53) \\
& \mu=10 \cdot 36 \times 10^{-5} .
\end{aligned}
$$

The mutation rate of NF-1 therefore appears to be in the region of $3 \cdot 1$ to $10 \cdot 4 \times 10^{-5}$.

ANALYSIS OF PARENTAL AGE AND MUTATION Birth order effect

Two out of 41 of the cases classified as new mutations were the parents' only child and for six

\begin{tabular}{|c|c|c|c|c|c|c|c|c|c|c|c|c|}
\hline \multirow{2}{*}{$\begin{array}{l}\text { Sibship } \\
\text { size }\end{array}$} & \multicolumn{12}{|c|}{ Birth order } \\
\hline & 1 & 2 & 3 & 4 & 5 & 6 & 7 & 8 & 9 & 10 & 11 & Total \\
\hline 2 & 6 & 4 & & & & & & & & & & 10 \\
\hline 3 & 2 & 3 & 1 & & & & & & & & & 6 \\
\hline 4 & - & 2 & 2 & 1 & & & & & & & & 5 \\
\hline 5 & - & - & - & - & 1 & & & & & & & 1 \\
\hline 6 & - & 2 & 1 & - & 2 & & & & & & & 5 \\
\hline 7 & - & - & - & 1 & - & - & 1 & & & & & 2 \\
\hline 9 & - & - & - & - & - & - & - & 1 & 1 & & & 2 \\
\hline 10 & - & - & - & - & - & 1 & - & - & - & - & & 1 \\
\hline 11 & - & - & - & - & - & - & - & - & 1 & - & - & 1 \\
\hline Total & 8 & 11 & 4 & 2 & 3 & 1 & 1 & 1 & 2 & - & - & 33 \\
\hline
\end{tabular}
out of 41 inadequate information was available for analysis of birth order. The birth order data for the remaining 33 cases are shown in table 2 . Using the

TABLE 2 Distribution of 33 new mutations by birth order.

Observed $6 A=624$. Theoretical $6 A=537$. Variance of $6 A=2481$.

$Z=\frac{\text { Observed } 6 A-\text { theoretical } 6 A}{\text { Standard error of } 6 A}=\frac{624-537}{\sqrt{2481}}=1 \cdot 747: p=0.081$. method of Haldane and $\mathrm{Smith}^{26}$ to analyse the data, no significant birth order effect was found $(p=0 \cdot 08)$.

\section{Parental ages of mutations}

The observed ages for parents of cases classified as being new mutations were compared with expected ages using the method described by Bundey et al. ${ }^{27}$ Therefore, the expected maternal age, adjusted for parity, was taken directly from the Registrar General's population data and the expected paternal age calculated by adding the expected mean difference in age between spouses. Accurate parental dates of birth were known for 29 of 41 presumed new mutations, but maternal ages adjusted for parity are only available from 1938; therefore, only 21 of 29 who were born after 1938 were used in analysis. The results are presented in table 3. No parental age effect was found, nor was the parental age difference significantly different from expected. A further analysis of parental age was performed on 15 of 21 new mutations in which both parents had been examined, and no significant parental effect was found $(p=0.55)$.

\section{PARENTAL EFFECT ON SEVERITY}

A total of $124 / 135$ ascertained cases was included in this analysis; the remaining 11 cases were excluded either because of inadequate pedigree or clinical information. The severity grades for these patients were analysed using analysis of variance with parental disease status (affected father, affected mother, new mutation) and age (under 18,18 or more years) as factors. The results are shown in table 4 . There were no overall differences between the status categories $(p=0 \cdot 84)$ or between the age groups $(p=0 \cdot 31)$. However, there was a significant interaction between age and status $(p=0.012)$,

\begin{tabular}{|c|c|c|c|}
\hline$n=21$ & $\begin{array}{l}\text { Mean } \\
\text { paternal } \\
\text { age }(y)\end{array}$ & $\begin{array}{l}\text { Mean } \\
\text { maternal } \\
\text { age }(y)\end{array}$ & $\begin{array}{l}\text { Mean paternal } \\
\text { maternal age } \\
\text { difference }(y)\end{array}$ \\
\hline Observed & $29 \cdot 62$ & $27 \cdot 68$ & 1.94 \\
\hline Expected & 29.91 & 27.62 & $2 \cdot 29$ \\
\hline $\begin{array}{l}\text { Mean observed- } \\
\text { expected }\end{array}$ & & & \\
\hline difference & -0.29 & 0.06 & -0.34 \\
\hline Standard error & & & \\
\hline$t^{*}$ of differences & $\begin{array}{r}1.04 \\
-0.28\end{array}$ & $\begin{array}{l}0.95 \\
0.06\end{array}$ & $\begin{array}{r}0.57 \\
-0.60\end{array}$ \\
\hline p & 0.79 & 0.95 & 0.55 \\
\hline
\end{tabular}
indicating that the young new mutations tended to be more severely affected than the older new

TABLE 3 Mean parental ages of NF-1 cases classified as new mutations and born after $1938(n=21)$ compared with parental ages in the general population.

*One sample $t$ test of whether mean observed-expected difference was different from zero $(\mathrm{df}=20)$. 
TABLE 4 Mean severity grade of 124 cases of NF-1 classified by disease status of parents and analysis of variance between groups.

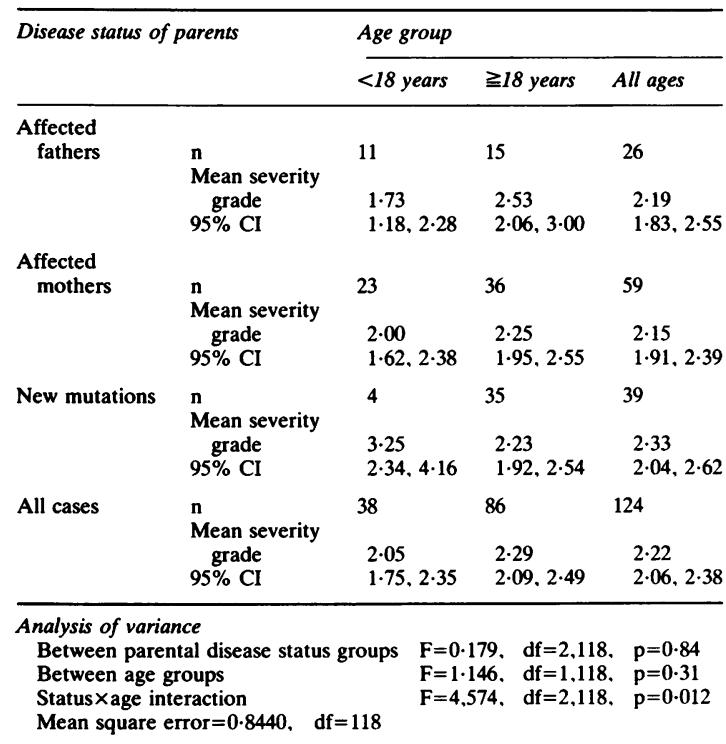

mutations; this was presumed to be the result of ascertainment bias.

\section{Discussion}

In a population based study of NF-1 in south east Wales we have identified 69 families with one or more affected subjects. Segregation analysis of the children of adult index cases showed no significant departure from the expected 1:1 ratio for a dominant disorder. In the pedigrees studied, there were 46 examples of at least three generation transmission of the disease and all obligate heterozygotes satisfied the diagnostic criteria for NF-1 agreed at the National Institutes of Health Consensus Conference on Neurofibromatosis. ${ }^{28}$ Our experience leads us to agree with Riccardi and Lewis ${ }^{29}$ that in descendants of patients with well characterised NF-1, penetrance is virtually $100 \%$ by the age of five years, when affected subjects will have developed CAL spots. ${ }^{30}$ We are aware of only three published cases of apparent non-penetrance of NF-131; one other previously reported case has since been retracted. ${ }^{17} 32$

There was no history of the disease in preceding generations or their sibs in 41 of 135 cases identified (table 2) and segregation analysis of their offspring again showed no departure from the expected 1:1 ratio. We identified no families where apparently normal parents had more than one affected child and no parents of apparently isolated cases with variant expression of the NF-1 phenotype, although a few such occurrences are recorded in published reports. Riccardi and Lewis ${ }^{29}$ reported two cases of affected sibs with normal parents and a further two families in which one parent appeared to have limited expression of the NF-1 gene. In one, a mother of two affected sons had bilateral Lisch nodules as her only disease manifestation and, in the other, the father of an affected son had a cervical schwannoma and two peripheral neurofibromas. Rubenstein $e t a^{33}$ reported two other families; in one a father and daughter both appeared to have segmental NF and in the other the father of a boy with NF-1 had six neurofibromas and one CAL spot on his left flank. We are aware of one further case (M Super, 1987, personal communication) in which the father of a girl with NF-1 had unilateral axillary freckling and a CAL spot on the adjacent arm as his only features.

Germline mosaicism is the most obvious explanation for apparently normal parents having more than one affected child, but the cases with limited expression of NF-1 in the parent are more difficult to explain. These cases could, however, be gonosomal mosaics; experimental work in the mouse and the available evidence in man suggest that the cells of the primitive ectoderm are multipotential. ${ }^{34} \mathrm{~A}$ single mutation of the NF-1 gene at this stage of development could therefore result in apparent segmental disease manifestations and gonadal involvement; other possible explanations are discussed by Riccardi and Lewis. ${ }^{29}$ In the clinical setting these rare and unusual cases mean that detailed clinical assessment, including slit lamp examination of the iris, is essential in assessing parents of apparently isolated cases. It is also difficult, in the light of these examples, fully to reassure patients with apparent segmental NF (reviewed by Carey et al ${ }^{32}$ ) that there is no risk of NF-1 occurring in their offspring, although with available information it is impossible to quantify this risk.

The minimum prevalence of NF-1 in the general population based on this study is $1 / 4950$ or $20 / 10^{5}$ of the population. This compares with prevalences from the three previous studies of between $1 / 2500$ and $1 / 7800$ (table 1 ). The figure of $1 / 7800$ from the USSR $^{7}$ would seem to be a significant underascertainment, in the light of the other studies, and that of Crowe $e a^{5}$ may be an overestimate as it is based on a summary of three approaches, each with wide margins of error and none population based. Nevertheless, the actual birth incidence of the NF-1 gene may be as high as the frequency estimated by Crowe et $a{ }^{5}{ }^{5}$ the decreased prevalence in the general population being accounted for both by underascer- 
tainment and increased mortality. Elsewhere, ${ }^{20}$ we have presented data suggesting an increased mortality in NF-1 and this was also shown by Sorenson et $a l^{35}$ in the 39 year follow up study of the cases originally identified by Borberg. ${ }^{4}$ The true incidence of NF-1 could only be estimated by following a large cohort of children from birth, but the prevalence data we have presented for those aged under 20 years suggest it may be as frequent as $1 / 2558$ or $39 / 10^{5}$.

We have shown that the genetic fitness of NF-1 sufferers is just below half that of the general population, the effect being more marked in males $(0.31)$ than females $(0 \cdot 60)$. The relative fertility of NF-1 sufferers has been studied previously by Crowe $e t a l^{5}$ with similar results; the overall fitness in their study was 0.53 (males 0.41 and females $0 \cdot 75$ ). This reduction of fitness cannot be explained solely by severe intellectual handicap or disease complications causing severe morbidity or mortality before adulthood, since these are infrequent complications. ${ }^{30}$ Crowe et al ${ }^{5}$ showed that a significant contribution to decreased fitness in NF-1 is failure of affected subjects to marry, although married persons still showed a reduction $(0 \cdot 80)$. The reasons for this are not conclusive, but there is no evidence for pregnancy wastage so that the explanation may be an overall reduction in fecundity. Our original data set lacked certain details necessary for further analysis but this is being addressed in a second study (M Littler, S Huson, N Morton, work in progress).

Our analyses of the mutation rate for the NF-1 gene compare with those of previous studies shown in table 1 and confirm that the gene for NF-1 has one of the highest mutation rates yet identified in man. We have been unable to show a significant birth order or parental age effect for new mutations. This was also the case in the study of Samuelsson, ${ }^{36}$ who found no parental age $(n=25)$ or birth order $(n=28)$ effect. However, two studies have shown one or both of these effects, both studying larger numbers of patients. Sergeyev ${ }^{7}$ pooled data from his own and three previous studies to analyse birth order in 193 sibships and, although none of the studies when analysed individually showed a significant birth order, the pooled data did. Sufferers were born later than normal sibs both when whole sibships $(p=0.004)$ and sibships without the last sib $(p=0.03)$ were analysed. The 56 cases in Sergeyev's own study also showed weak paternal, but no maternal, age increase over population controls, the paternal age increase being 1.99 years $(p=0.03)$. Riccardi et $\mathrm{l}^{37}$ were able to study the parental age at birth of a much larger number of NF-1 new mutations. They found the paternal age to be raised by $3 \cdot 15$ years $(n=187$, $p<0.001)$ and maternal age by 1.39 years $(n=171$, $\mathrm{p}<0 \cdot 001)$. Further analysis, however, showed that the increase in maternal age was solely accounted for by the increase in paternal age but not vice versa.

The birth order data on the small number in our study $(n=33, p=0.08)$ do suggest that had a larger number of families been studied a significant effect may have been seen. However, this is not the case for the paternal age figures where we have found no suggestion of an effect. A possible explanation for the different results is ascertainment bias in the population studied by Riccardi et al. ${ }^{37}$ The cases analysed were drawn from a population referred to a special interest clinic and it may be that older parents of new mutations are more likely to seek specialist referral, resulting in a biased sample. Overall, we must conclude that if an increased parental age effect does exist for NF-1, it is small when compared with other disorders such as achondroplasia or Apert's syndrome. ${ }^{38}$

A possible maternal effect on severity of NF-1 was first suggested by Miller and Hall ${ }^{16}$ in 1978. Studying 62 cases aged less than 18 years, ascertained through the records of a children's orthopaedic and university hospital, they found an increased severity in children born to affected mothers compared with those having affected fathers or new mutations. Two further reports ${ }^{17} 18$ and our own study have not confirmed this effect in a combined total of 443 NF-1 sufferers.

In summary, our study has confirmed that NF-1 is one of the most frequent dominant disorders, with virtually $100 \%$ penetrance by the age of five years and a high mutation rate. We were unable to show a paternal age effect for new mutations nor a maternal effect on severity of disease. The recent rapid advances towards the isolation of the NF-1 gene mean that the observations of clinical genetic studies will soon begin to be explained by the study of the gene at the molecular level.

We are grateful to the patients and their families, doctors who referred patients to the study, staff who retrieved case notes, Professor R Marks and Dr G Cole for allowing access to their respective histology indices, Professor N Morton for helpful discussions about methods of analysis, and Mrs S Kingsley for secretarial services. This study was supported by grants from the Wolfson Foundation and Action Research for the Crippled Child.

\footnotetext{
References

1 Virchow R. Ueber die Reform der patologischen und therapeutische Anschauungen durch die mikroskopischen untersuchungen. Virchows Arch [A] 1847;1:207-55.

2 Thomson A. On neuroma and neurofibromatosis. Edinburgh: Turnbull and Spears, 1900.
} 
${ }^{3}$ Preiser SA, Davenport CB. Multiple neurofibromatosis (von Recklinghausen disease) and its inheritance. Am J Med Sci 1918;156:507-41.

${ }^{4}$ Borberg A. Clinical and genetic investigations into tuberous sclerosis and Recklinghausen's neurofibromatosis. Acta Psychiatr Neurol Scand 1951;suppl II:1-239.

${ }^{5}$ Crowe FW, Schull WJ, Neel JV. A clinical, pathological and genetic study of multiple neurofibromatosis. Springfield, Illinois: Charles C Thomas, 1956.

${ }^{6}$ Crowe FW. Axillary freckling as a diagnostic aid in neurofibromatosis. Ann Intern Med 1964;61:1142-3.

7 Sergeyev AS. On the mutation rate of neurofibromatosis. Hum Genet 1975;28:129-38.

8 Samuelsson B, Axelsson R. Neurofibromatosis. A clinical and genetic study of 96 cases in Gothenburg, Sweden. Acta Dermatol Venereol [Suppl] (Stockh) 1981;95:67-71.

9 Riccardi VM. Von Recklinghausen neurofibromatosis. N Engl J Med 1981;305:1617-27.

${ }^{10}$ Riccardi VM. Neurofibromatosis: clinical heterogeneity. Curr Probl Cancer 1982;7:1-34.

1 Barker D, Wright E, Nguyen K, et al. Gene for von Recklinghausen neurofibromatosis is in the pericentromeric region of chromosome 17. Science 1987;236:1100-2.

12 Seizinger BR, Rouleau GA, Ozelius LG, et al. Genetic linkage of von Recklinghausen neurofibromatosis to the nerve growth factor receptor gene. Cell 1987;49:589-94.

13 Seizinger BR, Martuza RL, Gusella JF. Loss of genes on chromosome 22 in tumorigenesis of human acoustic neuroma. Nature 1986;322:644-7.

14 Rouleau G, Seizinger BR, Ozelius LG, et al. Genetic linkage analysis of bilateral acoustic neurofibromatosis to a DNA marker on chromosome 22. Nature 1987;329:246-8.

is Huson SM, Meredith AL, Sarfarazi M, Shaw DJ, Compston DAS, Harper PS. Linkage analysis of peripheral neurofibromatosis (von Recklinghausen disease) and chromosome 19 markers linked to myotonic dystrophy. J Med Genet 1986;23: 55-7.

${ }^{16}$ Miller M, Hall JG. Possible maternal effect on severity of neurofibromatosis. Lancet 1978;2:1071-3.

17 Carey JC, Laub JM, Hall BD. Penetrance and variability of neurofibromatosis: a genetic study of 60 families. Birth Defects 1979;15(5B):271-81.

${ }^{18}$ Riccardi VM, Wald JS. Discounting an adverse maternal effect on severity of neurofibromatosis. Pediatrics 1987;79:386-93.

19 Brasfield RD, Das Gupta TK. Von Recklinghausen's disease: a clinico-pathological study. Ann Surg 1972;175:86-104.

${ }^{20}$ Huson SM, Harper PS, Compston DAS. Von Recklinghausen neurofibromatosis: a clinical and population study in south east Wales. Brain 1988;111:1355-81.

21 Lewis RA, Riccardi VM. Von Recklinghausen neurofibromatosis. Incidence of iris hamartomata. Ophthalmology 1981; 88:348-54

22 Riccardi VM, Kleiner B. Neurofibromatosis: a neoplastic birth defect with two age peaks of severe problems. Birth Defects 1977;12(3C):131-8.

${ }^{23}$ Emery AEH. Methodology in medical genetics. Edinburgh: Churchill Livingstone, 1986.

${ }^{24}$ Tanaka K. A new simplified method for estimating relative fitness in man. Jinrui Idengaku Zasshi 1974;19:195-202.

25 Tanaka K. Estimation of relative fitness in human abnormalities with sex difference in selection intensity: a new simplified method. Jinrui Idengaku Zasshi 1975;20:183-6.

${ }^{26}$ Haldane JBS, Smith CAB. A simple exact test for birth-order effect. Ann Eugen 1947;14:117-24.

27 Bundey S, Harrison MJG, Marsden CD. A genetic study of torsion dystonia. J Med Genet 1975;12:12-19.

${ }^{28}$ National Institutes of Health Consensus Development Conference. Neurofibromatosis conference statement. Arch Neurol 1988;45:575-8.

29 Riccardi VM, Lewis RA. Penetrance of von Recklinghausen neurofibromatosis: a distinction between predecessors and descendants. Am J Hum Genet 1988;42:284-9.

${ }^{30}$ Huson SM, Compston LAS, Harper PS. A genetic study of von Recklinghausen reurofibromatosis in south east Wales. II Guidelines for genetic counselling $J$ Med Genet 1989;26:712-21.

31 Spence MA, Parry DM, Bader JL, et al. Genetic linkage analysis of neurofibromatosis. Ann NY Acad Sci 1986;486:287-92.

32 Carey JC, Baty BJ, Johnson JP, Morrison T, Skolnick M, Kivlin J. The genetic aspects of neurofibromatosis. Ann NY Acad Sci 1986;486:45-56.

33 Rubenstein AE, Bader JE, Aron AA, Wallace S. Familial transmission of segmental neurofibromatosis. Neurology (Minneap) 1983;33(suppl 2):76.

34 Gardner RL. Cell lineage and cell commitment in the early mammalian embryo. In: Warshaw JB, ed. The biological basis of reproductive and developmental medicine. Amsterdam: Elsevier Science Publishing, 1983:31-41.

35 Sorenson SA, Mulvihill JJ, Nielsen A. Long-term follow-up of von Recklinghausen neurofibromatosis: survival and malignant neoplasms. N Engl J Med 1986;314:1010-5.

${ }^{36}$ Samuelsson B. Neurofibromatosis (von Recklinghausen's disease): a clinical-psychiatric and genetic study. MD thesis, University of Goteborg, Sweden, 1981.

37 Riccardi VM, Dobson CE, Chakraborty R, Bontke C. The pathophysiology of neurofibromatosis. IX. Paternal age as a factor in the origin of new mutations. Am J Med Genet 1984;18:169-76.

${ }^{38}$ Risch N, Reich EW, Wishnick MM, McCarthy JG. Spontaneous mutation and parental age in humans. Am J Hum Genet 1987;41:218-48.

Correspondence to Dr S M Huson, Department of Medical Genetics, Churchill Hospital, Headington, Oxford OX3 7LJ. 
APPENDIX (1) Breakdown of pedigree information based on parental details for 48 cases with no history of NF-1 in preceding generations or their sibs.

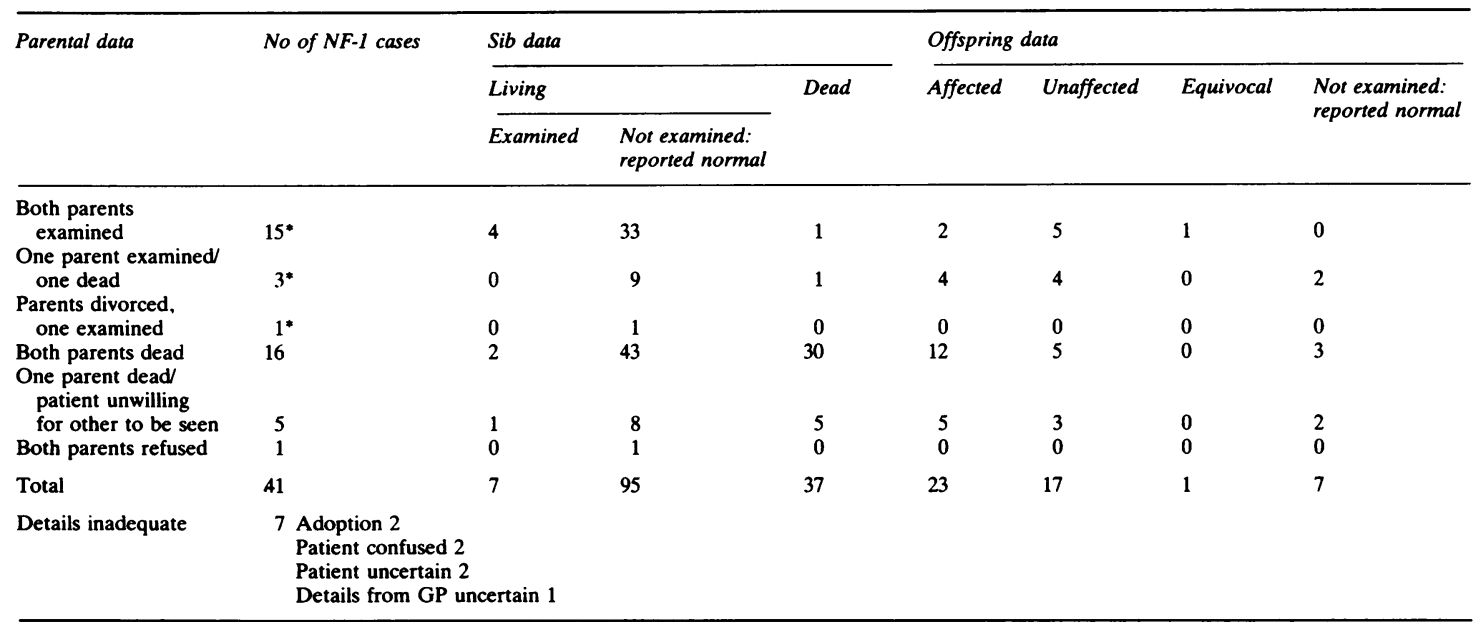

*In 20/34 parents slip lamp examination was performed.

APPENDIX (2) Estimation of fitness analysis.

Tanaka $^{24}$ has shown that

$$
\text { Relative fitness, } w=\frac{A p}{A_{0}}
$$

where $A p=$ frequency of trait among parents of index cases and $A_{0}=$ frequency of trait among offspring of index cases.

In the calculation of $\mathrm{Ap}$, four index cases were excluded since parental disease status was uncertain, and in families with more than one index case the parents of the oldest case were used; $29 / 130$ parents had NF-1 ( $A p=0.223$ ).

For the estimation of $A_{0}$, adult index cases where all their children had been examined and the disease status certain were used; $18 / 38$ were affected $\left(A_{0}=0.474\right)$, therefore:

$$
\text { Relative fitness, } w=\frac{0.223}{0.474}=0.470
$$

The relative fitness in males $\left(w^{1}\right)$ and females $\left(w^{11}\right)$ were determined using the formulae 25 .

$$
\text { and } \quad \begin{aligned}
w^{1} & =\frac{A p^{1}}{A_{0}} \times \frac{x^{1}+x^{11}}{2 x^{1}} \\
w^{11} & =\frac{A p^{11}}{A_{0}} \times \frac{x^{1}+x^{11}}{2 x^{11}}
\end{aligned}
$$

where $A p^{1}$ and $A p^{11}$ are the frequencies of the disease in fathers and mothers of index cases, respectively. $A_{0}{ }^{1}$ and $A_{0}{ }^{11}$ are the frequencies of affected subjects among children of male and female index cases and $x^{1}$ and $x^{11}$ the relative frequencies of affected males and females in the general population, respectively.

In the population studied $\mathrm{Ap}^{1}=11 / 65=0 \cdot 169 ; \mathrm{A}_{0}{ }^{1}=6 / 10=0 \cdot 6 ; \mathrm{Ap}^{11}=18 / 65=$ $0.277 ; A_{0}{ }^{1}=12 / 28=0.429 ; \quad x=60 / 324100=0.000185$ and $x^{11}=75 / 344000=$ $0 \cdot 000218$.

Therefore:

$$
w^{1}=\frac{0.169}{0.6} \times \frac{0.000403}{0.000370}=0.307
$$

and

$$
w^{11}=\frac{0.277}{0.429} \times \frac{0.000403}{0.000436}=0.597
$$

